\title{
Soluble Neural-cadherin as a novel biomarker for malignant bone and soft tissue tumors
}

\author{
Rui Niimi ${ }^{1}$, Akihiko Matsumine ${ }^{1 *}$, Takahiro lino', Shigeto Nakazora', Tomoki Nakamura', Atsumasa Uchida ${ }^{2}$ \\ and Akihiro Sudo ${ }^{1}$
}

\begin{abstract}
Background: Neural-cadherin ( $\mathrm{N}$-cadherin) is one of the most important molecules involved in tissue morphogenesis, wound healing, and the maintenance of tissue integrity. Recently, the cleavage of N-cadherin has become a focus of attention in the field of cancer biology. Cadherin and their ectodomain proteolytic shedding play important roles during cancer progression. The aims of this study are to investigate the serum soluble $\mathrm{N}$-cadherin ( $\mathrm{s} \mathrm{N}-\mathrm{CAD}$ ) levels in patients with malignant bone and soft tissue tumors, and to evaluate the prognostic significance of the sN-CAD levels.
\end{abstract}

Methods: We examined the level of serum sN-CAD using an ELISA in 80 malignant bone and soft tissue tumors (bone sarcoma, $n=23$; soft tissue sarcoma, $n=50$; metastatic cancer, $n=7$ ) and 87 normal controls. The mean age of the patients was 51 years (range, 10-85 years) and the mean follow-up period was 43 months (range, $1-115$ months).

Results: The median serum sN-CAD level was $1,267 \mathrm{ng} / \mathrm{ml}$ (range, $135-2,860 \mathrm{ng} / \mathrm{ml}$ ) in all patients. The mean serum sN-CAD level was 1,269 ng/ml (range, 360-2,860 ng/ml) in sarcoma patients, otherwise 1,246 ng/ml (range, $135-2,140 \mathrm{ng} / \mathrm{ml}$ ) in cancer patients. The sN-CAD levels in patient were higher than those found in the controls, who had a median serum level of $108 \mathrm{ng} / \mathrm{ml}$ (range, $0-540 \mathrm{ng} / \mathrm{ml}$ ). The patients with tumors larger than $5 \mathrm{~cm}$ had higher serum sN-CAD levels than the patients with tumors smaller than $5 \mathrm{~cm}$. The histological grade in the patients with higher serum sN-CAD levels was higher than that in the patients with lower serum sN-CAD levels. A univariate analysis demonstrated that the patients with higher serum $s \mathrm{~N}-\mathrm{CAD}$ levels showed a worse disease-free survival rate, local recurrence-free survival rate, metastasis-free survival rate, and overall survival rate compared to those with lower serum sN-CAD levels. In the multivariate analysis, sN-CAD was an independent factor predicting disease-free survival.

Conclusions: $\mathrm{SN}-\mathrm{CAD}$ is a biomarker for malignant bone and soft tissue tumors, and a potentially valuable pre-therapeutic prognostic factor in patients with bone and soft tissue sarcoma.

Keywords: Sarcoma, Cadherin, Prognosis, Shedding, Biomarker

\section{Background}

Musculoskeletal sarcoma is a rare malignancy. Despite the recent advances in treatment for these tumors, the prognosis is still poor. To improve the clinical outcomes of sarcoma patients, the discovery of the mechanisms of tumorigenesis and the identification of early biomarkers for determining the diagnosis/prognosis are required. In

\footnotetext{
*Correspondence: matsumin@clin.medic.mie-u.ac.jp

'Department of Orthopaedic Surgery, Mie University Graduate School of Medicine, Tsu, Japan

Full list of author information is available at the end of the article
}

particular, the identification of a biomarker that can predict patients at high-risk is important, because such a biomarker could be a useful indicator for determining whether adjuvant therapeutic modalities, such as irradiation and chemotherapy, should be utilized.

The etiology of tumors is multifactorial, and is believed to be the result of inappropriate cell growth, faulty cell differentiation and improper cell-cell and cell-extracellular matrix interactions. In particular, cell-cell adhesion is important in maintaining the tissue architecture. Cadherins are one of the most important proteins involved in cell-

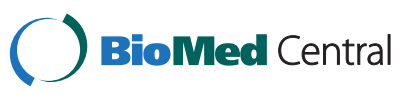


cell adhesion. The cadherins constitute a large multigene family of transmembrane glycoproteins that mediate calcium-dependent intercellular adhesion. More than 40 members of the cadherin family have been identified so far [1]. Cytoplasmic domain of the cadherin molecule can form a molecular complex with the catenin family, which link the cadherin to the actin cytoskeleton of the cell. The cadherin-dependent signaling affects fundamental cellular processes such as proliferation, survival, differentiation, cell shape and migration, which in turn influence the tissue morphogenesis and structure. The signaling is also involved in pathogenic events such as carcinogenesis and distant metastasis $[2,3]$. The loss of cell growth control and architecture disruption is hallmarks of oncogenic transformation. Previous studies have provided evidence that the loss of adhesiveness and increased invasive capacity of tumors cells are associated with a disruption of cell-cell adhesion mediated by malfunction or altered phosphorylation of the cadherin-catenin complex [4-7].

Recent studies showed that N-cadherin can be cleaved by ADAM10 (a disintegrin and metalloproteinase 10). The metalloproteinase domain of the enzyme is responsible for the initial step of $\mathrm{N}$-cadherin processing, which releases soluble active fragments into the extracellular space, and subsequently generates an intracellular C-terminal fragment (CTF) [8,9]. The CTF initiates signaling pathways through the cytoplasmic $\beta$-catenin pool. Therefore, the ADAM10-dependent cleavage of $\mathrm{N}$-cadherin modulates cell-cell adhesion, as well as signal transduction.

Recently, many researchers have reported that cadherins and their ectodomain shedding play important roles during cancer progression. A multitude of extracellular proteinases have been identified, and proteolytic shedding of the extracellular domain results in the generation of soluble E-, P- or N-cadherin ectodomains. Elevated levels of circulating soluble E- and P-cadherins have been described in cancer patients compared with healthy controls. For example, Chan et al. showed that the soluble E-cadherin concentration was significantly elevated in $67 \%$ of patients with gastric cancer [10]. Soluble N-cadherin (sN-CAD) can be found in the circulation of normal individuals, but is elevated in patients with breast, prostate and bladder carcinoma [11-14]. However, to date, there have been no studies that have investigated the use of the serum $\mathrm{sN}-\mathrm{CAD}$ levels as a diagnostic or predicting factor.

The aims of this study are to investigate the serum $\mathrm{sN}-\mathrm{CAD}$ levels in patients with malignant bone and soft tissue tumors, and to evaluate the prognostic significance of the $\mathrm{sN}-\mathrm{CAD}$ levels.

\section{Methods}

\section{Patient selection}

Serum samples were collected from 87 healthy subjects, 73 bone and soft tissue sarcoma patients, and 7 metastatic cancer patients with musculoskeletal metastases. The details of the clinicopathological features of 73 patients of the bone and soft tissue sarcoma are listed in Table 1. The mean follow-up period was 43 months (range, 1-115 months). The patient group included 36 males and 37 females, with a mean age of 51 years (range, 10-85 years) at the first presentation. There were 23 bone sarcomas, including 14 osteosarcomas (OS), 3 chondrosarcomas, 3 Ewing sarcomas, and 3 chordomas. There were also 50 soft tissue sarcomas, including 10 malignant fibrous histiocytomas (MFH), 9 liposarcomas (5 myxoid liposarcomas, 2 pleomorphic liposarcomas, and 2 dedifferentiated liposarcomas), 6 malignant peripheral nerve sheath tumors (MPNST), 3 synovial sarcomas, 3 dermatofibrosarcoma protuberans, 3 rhabdomyosarcomas, 2 epithelioid sarcomas, 2 clear cell sarcomas, an extraskeletal chondrosarcoma, an

Table 1 Patient and tumor characteristics

\begin{tabular}{|c|c|}
\hline Factor & $\begin{array}{l}\text { No. of patients } \\
\qquad(\mathrm{N}=73)\end{array}$ \\
\hline \multicolumn{2}{|l|}{ Gender } \\
\hline Male & 36 \\
\hline Female & 37 \\
\hline \multicolumn{2}{|l|}{ Age (years) } \\
\hline$\leqq 49$ & 32 \\
\hline$\geqq 50$ & 41 \\
\hline \multicolumn{2}{|l|}{ Size $(\mathrm{cm})$} \\
\hline $5<$ & 17 \\
\hline $5 \geqq$ & 56 \\
\hline \multicolumn{2}{|l|}{ Location ${ }^{1}$} \\
\hline Upper extremities & 7 \\
\hline Lower extremities & 39 \\
\hline Trunk & 25 \\
\hline \multicolumn{2}{|l|}{ Depth } \\
\hline Superficial & 6 \\
\hline Deep & 67 \\
\hline \multicolumn{2}{|l|}{ Histological grading } \\
\hline low grade & 13 \\
\hline high grade & 60 \\
\hline \multicolumn{2}{|l|}{ Tumor condition } \\
\hline Primary & 50 \\
\hline Recurrent tumor & 17 \\
\hline Metastatic tumor & 6 \\
\hline \multicolumn{2}{|l|}{ Soluble cadherin } \\
\hline$<1,500 \mathrm{ng} / \mathrm{ml}$ & 52 \\
\hline$\geqq 1,500 \mathrm{ng} / \mathrm{ml}$ & 21 \\
\hline
\end{tabular}

${ }^{1}$ two patients with multiple sarcomas were excluded. 
extraskeletal osteosarcoma, a myxofibrosarcoma, a malignant granular cell tumor, and 8 unclassifiable spindle cell sarcomas. There were six metastatic cancer to the bone ( 2 thyroid cancers, 2 renal cancers, 1 lung cancer, and 1 multiple myeloma), and one metastatic cancer to the soft tissue (squamous cell carcinoma). A histological grading of the bone sarcoma was performed according to the grading system proposed by Borders AC [15] and a histological evaluation of soft tissue sarcoma was performed using the grading system of the French Federation of Cancer Centers Sarcoma Group system [16]. The histological grading in soft tissue sarcoma was low grade (grade 1) in 9 sarcomas and in high grade 41 sarcomas (grade 2:20, grade 3:21), while the histological grading in bone sarcoma was low grade in 4 sarcomas and high grade in 19 sarcomas. All patients underwent a complete tumor resection with a wide margin during the initial surgery at our hospital. The diagnoses were primarily based on the morphological appearance based on the results of their reactivity for immunostaining. The 73 samples consisted of 50 primary lesions, 17 local recurrences, and 6 metastases.

At the final follow-up, 26 patients were continuously disease-free, 13 patients had no evidence of disease, 15 patients were alive with disease, and 19 patients died of disease.

The control subjects comprised 28 males and 59 females. The mean age of the control subjects was 46 years (range, 19-89 years). Almost all control subjects younger than 60 years old were healthy volunteers without any medical history of cancer. Those over 60 years of age had conditions such as osteoarthritis, osteoporosis, and so on, and all had C-reactive protein values below $0.5 \mathrm{mg} / \mathrm{dl}$.

This study is in compliance with the principles of the Declaration of Helsinki and written informed consent was obtained from all of the patients included in this study.

\section{Serum sample collection and storage}

Fifty-one serum samples were obtained at open biopsy or initial surgical excision before administration of any chemotherapeutic agent. Seventeen serum samples were obtained at the excision of recurrent tumor. Five serum samples were obtained at the excision of the metastatic lesion. Longitudinal change of the SN-CAD was measured by measuring the serum level at the pre- and postoperative day in a metastatic epitheliod sarcoma patient. Venous blood samples were collected and centrifuged at $2,500 \mathrm{~g}$ for $10 \mathrm{~min}$. All sera were stored at $-80^{\circ} \mathrm{C}$ until measurement. All samples were collected under the approval of the ethics committee of the Mie University Graduate School of Medicine.

\section{Immunoenzymometric assay for the sN-CAD levels}

The immunoenzymometric assay for the sN-CAD levels was performed using a home-made ELISA plate, as described in a previous report [17]. All serum samples were diluted 5 times in PBS containing $0.1 \%$ bovine serum albumin (BSA). A dilution series of recombinant $\mathrm{N}$-cadherin from 1 to $1,000 \mathrm{ng} / \mathrm{ml}$ was prepared (recombinant human $\mathrm{N}$-cadherin/Fc chimera, R\&D Systems, Abingdon, UK). A 96 well immunoplate (CN-469949, Nalge Nunc International, Denmark) was coated with $75 \mu \mathrm{l}$ of the diluted sample overnight at $4^{\circ} \mathrm{C}$. The wells were washed with PBS/0.05\% Tween-20 and quenched at $37^{\circ} \mathrm{C}$ with PBS/1\% BSA for $1 \mathrm{hr}$. Next, the plates were washed again (4 times) and incubated with the primary antibody (Mouse GC-4 antibody, Sigma, St. Louis, MO; 1/200 in $\mathrm{PBS} / 0.1 \% \mathrm{BSA})$ at $37^{\circ} \mathrm{C}$ for $2 \mathrm{hr}$. The plates were then washed again (4 times), and subsequently incubated with a mouse secondary antibody linked to alkaline phosphatase (Goat anti-mouse linked to alkaline phosphatase, Sigma, St. Louis, MO; 1/3,000). The substrate, p-nitrophenylphosphate (N2765, Sigma, St. Louis, MO), was added to the plates, and after $30 \mathrm{~min}$, the optical density of each well was determined with a microplate reader (Molecular Devices, Wokingham, UK) at $405 \mathrm{~nm}$. Measurements were done at least in a triplet for each sample, and the mean value was calculated.

\section{Statistical analysis}

The Mann-Whitney $U$ test was used to analyze the association of the serum sN-CAD levels between healthy subjects and patients. The Mann-Whitney $U$ test was also used to analyze the associations between the serum $\mathrm{sN}-\mathrm{CAD}$ levels and the clinicopathological variables, such as the type of tumor (bone or soft tissue sarcoma), age, tumor depth, tumor size, histological grade, and the type of malignancy (primary or recurrence/metastasis). We defined the cut-off level of $\mathrm{sN}-\mathrm{CAD}$ at $1,500 \mathrm{ng} / \mathrm{ml}$ to identify the high-risk patient group. The disease-free survival (DFS) was defined as the time from the initial treatment to the date of clinically documented local recurrence/metastasis. The local recurrence-free survival (LRFS) was defined as the time from the initial treatment to the date of clinically documented local recurrence. The metastasis-free survival (MFS) was defined as the time from the initial treatment to the date of clinically documented distant metastasis. The overall survival (OS) was defined as the time from the initial treatment to the date of death from any cause. For the multivariate analysis, a Cox proportional hazards regression model was used to identify the statistically significant differences in the survival and to estimate hazard ratios and 95\% confidence intervals. The prognostic variables by the univariate analysis with a $\mathrm{p}<0.2$ (age, tumor size, histological grading, and $\mathrm{sN}-\mathrm{CAD}$ ) were entered into a 
Cox multivariate analysis model. A p value $<0.05$ was considered to be significant. The analysis was performed using the StatView statistical software package (version 5.0; SAS Institute, Cary, NC, USA). The statistical analysis was performed by N.R. and M.A., and both of whom have responsibility for the results of statistical analysis.

\section{Results}

Serum sN-CAD levels in sarcoma patients, cancer patients, and control subjects

The mean serum sN-CAD level was 1,267 ng/ml (range, $135-2,860 \mathrm{ng} / \mathrm{ml}$ ) in all patients. The mean serum $\mathrm{sN}-\mathrm{CAD}$ level was $1,269 \mathrm{ng} / \mathrm{ml}$ (range, 360-2,860 ng/ml) in sarcoma patients, otherwise 1,246 ng/ml (range, 135$2,140 \mathrm{ng} / \mathrm{ml}$ ) in cancer patients with musculoskeletal metastases. The levels measured in the patients were higher than those found in the controls, who had a mean serum level of $108 \mathrm{ng} / \mathrm{ml}$ (range, $0-540 \mathrm{ng} / \mathrm{ml}$; p < 0.01, Figure 1). sN-CAD levels in the major sarcoma subgroups and control subjects were indicated in Figure 2. In the controls, levels of sN-CAD under $500 \mathrm{ng} / \mathrm{ml}$ were observed, whereas in the sarcoma patients, a wide distribution of sN-CAD levels was observed. Longitudinal change of the sN-CAD was measured in a metastatic epitheliod sarcoma patient. The serum sN-CAD level showed $700 \mathrm{ng} / \mathrm{ml}$ just before tumor excision and $525 \mathrm{ng} / \mathrm{ml}$ on the next day after surgery.

\section{Associations between the serum SN-CAD level and the clinicopathological variables}

The Mann-Whitney $U$ test was used to analyze the associations between the serum sN-CAD levels and the clinicopathological variables (Table 2). The patients with tumors larger than $5 \mathrm{~cm}$ had higher serum $\mathrm{sN}-\mathrm{CAD}$ levels than the patients with tumors smaller than $5 \mathrm{~cm}$. The histological grade in the patients with higher serum sN-CAD levels was higher than that in the patients with lower serum sN-CAD levels. The levels of serum sN-CAD were not also associated with the type of tumor (bone or soft tissue sarcoma), tumor location, or the condition (primary or recurrence/metastasis) of the lesion.

\section{Prognostic analysis}

\section{The disease-free survival rate and predictors of events}

We next compared the OS, DFS, LRFS, and MFS between the patients with high serum sN-CAD levels and the patients with low serum sN-CAD levels. Patients with high $\mathrm{sN}-\mathrm{CAD}$ levels had a poorer DFS than the patients with low sN-CAD levels $(\mathrm{p}=0.0022$, Table 3$)$. The estimated DFS at 1, 3 and 5 years was $30.0 \%, 15.0 \%$, and $0 \%$, respectively, versus $65.7 \%, 55.1 \%$, and $55.1 \%$, respectively, for patients with high and low sN-CAD levels (Figure 3). A univariate analysis also revealed that there was a significantly poorer outcome for patients with a high tumor histological grade $(\mathrm{p}=0.0334$, Table 3$)$. The multivariate analysis demonstrated that the $\mathrm{sN}-\mathrm{CAD}$ levels is an independent prognostic factor $(\mathrm{p}=0.0132$; Table 4).

\section{Local recurrence-free survival rate and predictors of events}

The patients with high sN-CAD levels had a poorer LRFS than the patients with low sN-CAD levels $(p=0.0123$, Table 3). The estimated LRFS at 1,3 and 5 years was

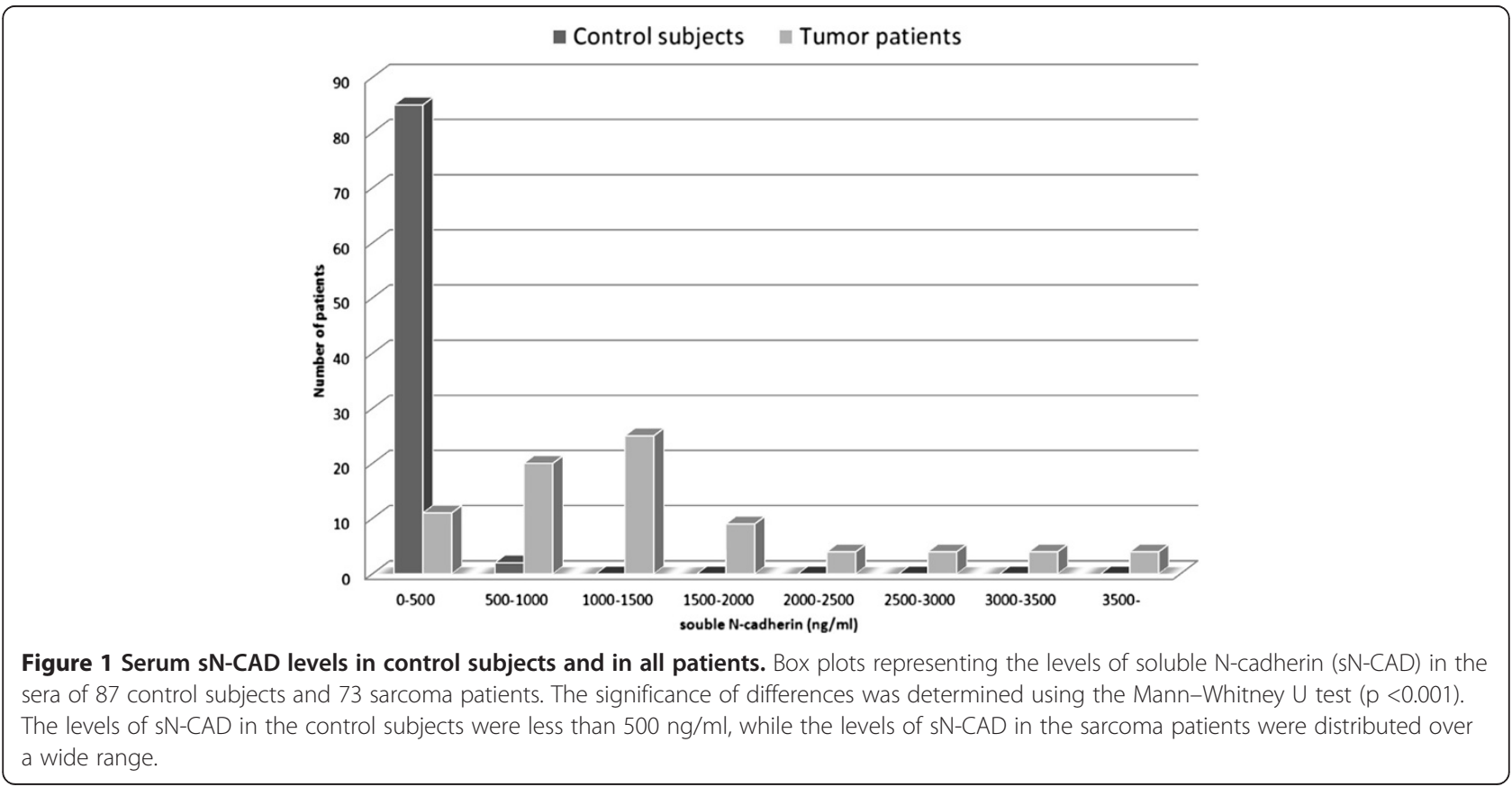




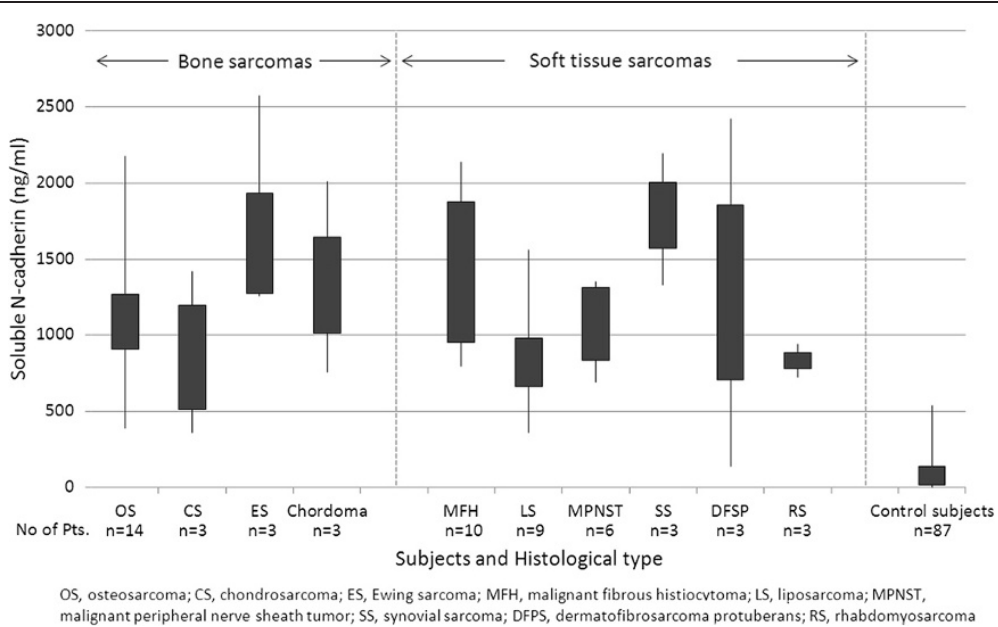

Figure 2 Distrubution of $\mathbf{s N}$-CAD Levels in sarcoma patient $\mathbf{s}$ and in control subjects. Boxplot showed sN-CAD levels separately for the major bone sarcomas, soft tissue sarcomas and control subjects.

$60.6 \%, 60.6 \%$, and $60.6 \%$, respectively, versus $91.7 \%$, $87.9 \%$ and $83.5 \%$ respectively, for patients with high and low sN-CAD levels (Figure 4). The high sN-CAD levels lost their prognostic significance in the multivariate analysis $(\mathrm{p}=0.1743)$.

The metastasis-free survival rate and predictors of events The patients with high $\mathrm{sN}-\mathrm{CAD}$ levels had a poorer MFS than the patients with low sN-CAD levels $(p=0.0107$,

Table 2 The results of the univariate analysis of the associations between the serum soluble $\mathrm{N}$-cadherin levels and the clinicopathological variables

\begin{tabular}{|c|c|c|c|}
\hline $\begin{array}{l}\text { Clinicopathological } \\
\text { valiables }\end{array}$ & $\begin{array}{c}\text { No of } \\
\text { patients }\end{array}$ & $\begin{array}{c}\text { Soluble N-cadherin } \\
(\mathrm{ng} / \mathrm{ml})\end{array}$ & $p$ Value \\
\hline Bone tumor & 23 & $1,281(560-2,575)$ & 0.8914 \\
\hline Soft tissue tumor & 50 & $1,264(360-2,860)$ & \\
\hline Age (years) & & & 0.4665 \\
\hline$\leqq 49$ & 32 & $1,232(525-2,860)$ & \\
\hline$\geqq 50$ & 41 & $1,298(360-2,580)$ & \\
\hline Tumor size $^{1}$ & & & 0.0362 \\
\hline$<5 \mathrm{~cm}$ & 17 & $1,025(360-1,900)$ & \\
\hline$\geqq 5 \mathrm{~cm}$ & 56 & $1,343(360-2,860)$ & \\
\hline Depth $^{2}$ & & & 0.5402 \\
\hline Superficial & 6 & $1,364(390-2,180)$ & \\
\hline Deep & 67 & $1,261(360-2,860)$ & \\
\hline Histological grading & & & 0.0482 \\
\hline Low grade & 14 & $1,050(540-2,575)$ & \\
\hline High grade & 59 & $1,321(360-2,860)$ & \\
\hline Primary tumor & 51 & $1,246(360-2,860)$ & 0.4819 \\
\hline $\begin{array}{l}\text { Recurrent / metastatic } \\
\text { tumor }\end{array}$ & 22 & $1,323(390-2,575)$ & \\
\hline
\end{tabular}

${ }^{1}$ two patients with multiple sarcomas were excluded.
Table 3). The estimated MFS at 1, 3 and 5 years was $43.7 \%$, $43.7 \%$, and $34.9 \%$, respectively, versus $63.1 \%$, 55.4\% and $51.0 \%$, respectively, for the high and low sN-CAD levels (Figure 5). A univariate analysis also revealed that there was a significantly poorer outcome for patients with large tumors $(\mathrm{p}=0.0159)$ and high tumor histological grades $(\mathrm{p}=0.0108)$ (Table 3$)$.

The overall survival rate and predictors of events

Patients with high sN-CAD levels had a poorer OS than the patients with low sN-CAD levels $(\mathrm{p}=0.0334$, Table 3 ). The estimated OS at 1,3 and 5 years was $84.0 \%, 50.4 \%$, and $50.4 \%$, respectively, versus $93.7 \%$, $78.4 \%$ and $73.0 \%$, respectively, for patients with high and low sN-CAD levels (Figure 6). A univariate analysis also revealed that there was a significantly poorer outcome for patients with high tumor histological grades $(p=0.004$, Table 3). However, both the high sN-CAD levels lost their prognostic significance in the multivariate analysis (Table 5).

\section{Discussion}

In the present study, we found that the serum levels of sN-CAD in patients with malignant bone and soft tissue tumors were higher than those in control subjects. Both the tumor size and the histological grade were positively correlated to the serum sN-CAD levels. The current univariate analyses showed that high serum sN-CAD levels were associated with a decreased OS, DFS, MFS, and LRFS. Multivariate analyses showed an association of a high serum sN-CAD level with a decreased DFS. These results suggest that $\mathrm{sN}-\mathrm{CAD}$ is a biomarker, and may potentially be valuable as a pre-therapeutic prognosic factor in patients with malignant bone and soft tissue tumors. To the best of our knowledge, this is the first 
Table 3 The univariate analyses of the association between patients prognosis and clinicopathological valiables

\begin{tabular}{|c|c|c|c|c|c|c|c|c|c|c|c|c|}
\hline $\begin{array}{l}\text { Clinicopathological } \\
\text { valiables }\end{array}$ & No & $\begin{array}{c}\text { 5-year } \\
\text { disease-free } \\
\text { survival } \\
\text { rate }(\%)\end{array}$ & $p$ Value $^{3}$ & No & $\begin{array}{c}5 \text {-year } \\
\text { local recurrence- } \\
\text { free survival } \\
\text { rate }(\%)\end{array}$ & $p$ Value $^{3}$ & No & $\begin{array}{c}\text { 5-year } \\
\text { metastasis- } \\
\text { free } \\
\text { survival } \\
\text { rate (\%) }\end{array}$ & $p$ Value $^{3}$ & No & $\begin{array}{c}\text { 5-year } \\
\text { overall } \\
\text { survival } \\
\text { rate (\%) }\end{array}$ & $p$ Value $^{3}$ \\
\hline \multicolumn{13}{|l|}{ Age (years) } \\
\hline$\leqq 49$ & 23 & $60.9 \%$ & 0.1603 & 25 & $90.0 \%$ & 0.0621 & 32 & $58.9 \%$ & 0.5899 & 32 & $81.8 \%$ & 0.0517 \\
\hline$\geqq 50$ & 32 & $30.5 \%$ & & 31 & $62.4 \%$ & & 40 & $46.1 \%$ & & 41 & $56.0 \%$ & \\
\hline \multicolumn{13}{|l|}{ Gender } \\
\hline Male & 26 & $50.2 \%$ & 0.5806 & 29 & $76.1 \%$ & 0.6890 & 36 & $60.4 \%$ & 0.4844 & 36 & $68.8 \%$ & 0.7350 \\
\hline Female & 29 & $35.4 \%$ & & 27 & $76.5 \%$ & & 36 & $44.8 \%$ & & 37 & $66.1 \%$ & \\
\hline \multicolumn{13}{|l|}{ Size $(\mathrm{cm})$} \\
\hline$<5$ & 14 & $66.1 \%$ & 0.0616 & 13 & $82.5 \%$ & 0.9879 & 17 & $43.5 \%$ & 0.0159 & 17 & $83.3 \%$ & 0.1327 \\
\hline$\geqq 5$ & 41 & $34.5 \%$ & & 43 & $73.4 \%$ & & 55 & $79.5 \%$ & & 56 & $63.0 \%$ & \\
\hline \multicolumn{13}{|l|}{ Depth } \\
\hline Superficial & 3 & $66.7 \%$ & 0.8647 & 3 & $66.7 \%$ & 0.6414 & 6 & $62.5 \%$ & 0.6888 & 6 & $75.0 \%$ & 0.7062 \\
\hline Deep & 52 & $42.1 \%$ & & 53 & $76.9 \%$ & & 66 & $51.0 \%$ & & 67 & $66.7 \%$ & \\
\hline \multicolumn{13}{|l|}{ Location $^{1}$} \\
\hline Trunk & 16 & $34.4 \%$ & 0.2593 & 13 & $65.6 \%$ & 0.3231 & 24 & $54.7 \%$ & 0.8741 & 25 & $69.4 \%$ & 0.7125 \\
\hline Extremity & 37 & $48.9 \%$ & & 43 & $77.9 \%$ & & 46 & $52.7 \%$ & & 46 & $67.1 \%$ & \\
\hline \multicolumn{13}{|l|}{ Histological grading } \\
\hline Low grade & 13 & $69.2 \%$ & 0.1171 & 13 & $100 \%$ & 0.1026 & 14 & $84.6 \%$ & 0.0108 & 14 & $91.7 \%$ & 0.0426 \\
\hline High grade & 42 & $31.4 \%$ & & 43 & $67.2 \%$ & & 58 & $58.4 \%$ & & 59 & $60.5 \%$ & \\
\hline \multicolumn{13}{|l|}{ Soluble Cadherin ${ }^{2}$} \\
\hline Low & 40 & $55.1 \%$ & 0.0022 & 40 & $83.5 \%$ & 0.0123 & 51 & $51.0 \%$ & 0.0107 & 52 & $73.0 \%$ & 0.0334 \\
\hline High & 15 & $0 \%$ & & 16 & $60.6 \%$ & & 21 & $34.9 \%$ & & 21 & $50.4 \%$ & \\
\hline
\end{tabular}

${ }^{1}$ two patients with multiple sarcoms were excluded.

${ }^{2}$ Low means $<1,500 \mathrm{ng} / \mathrm{ml}$, and high means $\geqq 1,500 \mathrm{ng} / \mathrm{ml}$.

${ }^{3}$ Log-rank test.

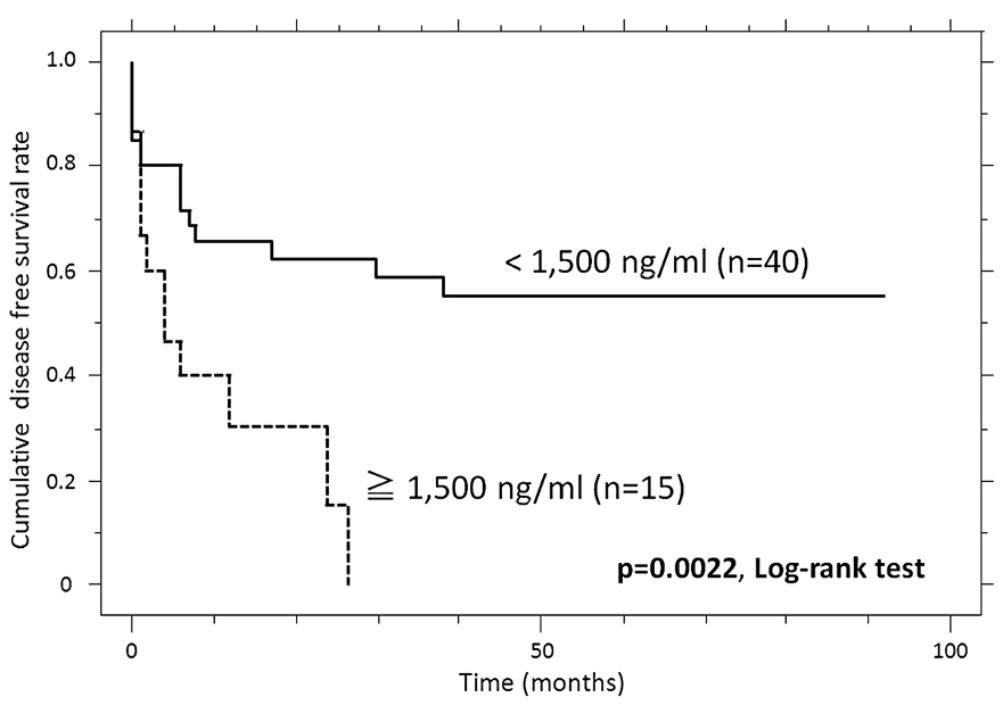

Figure 3 The cumulative disease-free survival (DFS) of patients with high SN-CAD levels, compared to patients with low sN-CAD levels. 


\begin{tabular}{|c|c|c|c|}
\hline $\begin{array}{l}\text { Clinicopathological } \\
\text { valiables }\end{array}$ & $\begin{array}{l}\text { Relative } \\
\text { risk }\end{array}$ & $\begin{array}{c}95 \% \text { confidence } \\
\text { interval }\end{array}$ & $p$ value \\
\hline Age (years) & 2.796 & $0.608-12.856$ & 0.1865 \\
\hline \multicolumn{4}{|l|}{$\leqq 49$} \\
\hline \multicolumn{4}{|l|}{$\geqq 50$} \\
\hline Size $(\mathrm{cm})$ & 1.474 & $0.279-7.796$ & 0.6483 \\
\hline \multicolumn{4}{|l|}{$<5$} \\
\hline \multicolumn{4}{|l|}{$\geqq 5$} \\
\hline Histological grading & 0.075 & $0.005-1.045$ & 0.0540 \\
\hline \multicolumn{4}{|l|}{ Low grade } \\
\hline \multicolumn{4}{|l|}{ High grade } \\
\hline Soluble Cadherin ${ }^{1}$ & 6.540 & $1.480-28.902$ & 0.0132 \\
\hline \multicolumn{4}{|l|}{ Low } \\
\hline High & & & \\
\hline
\end{tabular}

report which indicated the significance of $\mathrm{SN}-\mathrm{CAD}$ as a biomarker for prognosis in malignant bone and soft tissue tumor patients.

Recently, accumulating evidence has suggested epithelialmesenchymal transition (EMT) to play a critical role in cancer progression [18]. The EMT is defined by the loss of epithelial characteristics and the acquisition of a mesenchymal phenotype. The cell characteristics are highly affected during the EMT, resulting in altered cell-cell and cell-matrix interactions, and increased cell motility and invasiveness. In epithelial cancers, the EMT is characterized by a switch in cell membrane cadherins (from E- to N-cadherin), a change from apical-basal to front-back polarity and the acquisition of motility, enabled in part by the restructuring of the actin cytoskeleton [19]. The EMT is associated with the invasion and metastasis of various cancers [14,20-23]. Because sarcoma cells have a mesenchymal phenotype, $\mathrm{N}$-cadherin may be one of the key molecules involved in disease progression. However, only a small number of studies about Ncadherin expression in bone and soft tissue sarcoma have been reported. Laskin et al. [24] described that Ncadherin was observed in chordoma (100\%), biphasic synovial sarcoma (86\%), diffuse mesothelioma (70\%), malignant melanoma (56\%), epithelioid sarcoma (38\%), epithelioid angiosarcoma (25\%), poorly differentiated synovial sarcoma (15\%), clear cell sarcoma (10\%), and monophasic fibrous synovial sarcoma (4\%). Kashima et al. [25] found a reduced expression of N-cadherin on the osteosarcoma cell surface, and suggested that the reduced expression of $\mathrm{N}$-cadherin might be due to the proteolytic cleavage of the intact form into the secreted form. However, no study has so far assessed the relationship between the sN-CAD levels and their clinical significance in patients with bone and soft tissue tumors.

The present study showed that the serum sN-CAD levels were correlated with the tumor size $(p=0.02)$. The several possible causes of the increased levels of $\mathrm{sN}$ CAD in patients with larger tumors can be supposed. First possibility is that the sN-CAD levels may depend on the number of malignant cells. Larger tumor might have a higher sN-CAD level because they are composed of a higher number of cells. Second possibility is that the expression and/or shedding of $\mathrm{N}$-cadherin may increase in rapidly growing tumors. In the current study, the univariate analyses showed that high serum sN-CAD levels

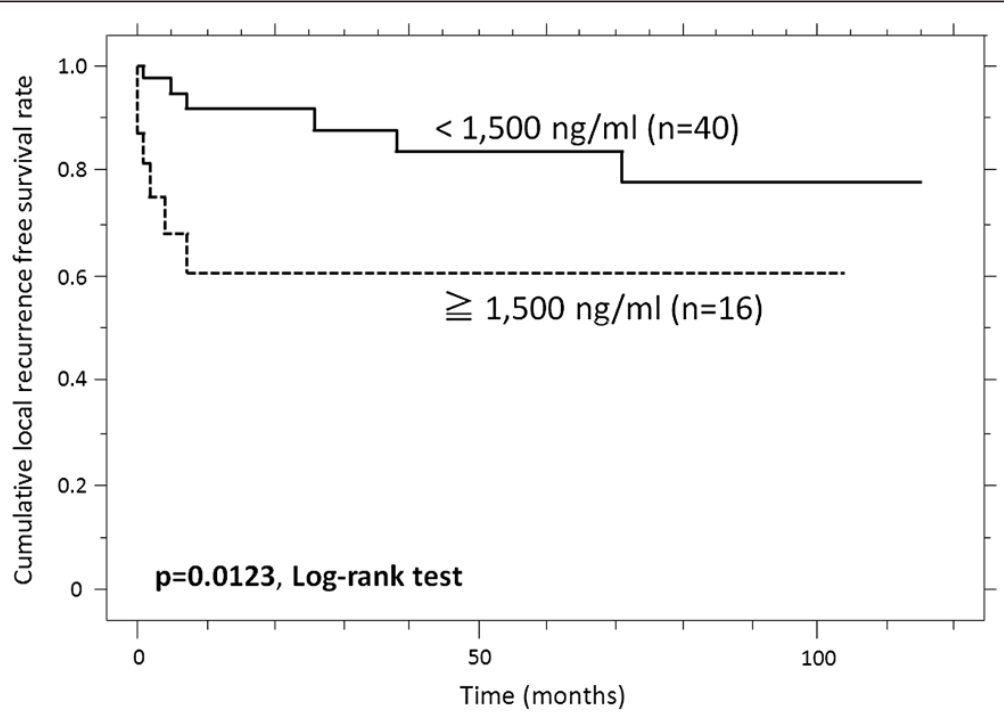

Figure 4 The cumulative local recurrence-free survival (LRFS) of patients with high sN-CAD levels, compared to patients with low sN-CAD levels. 


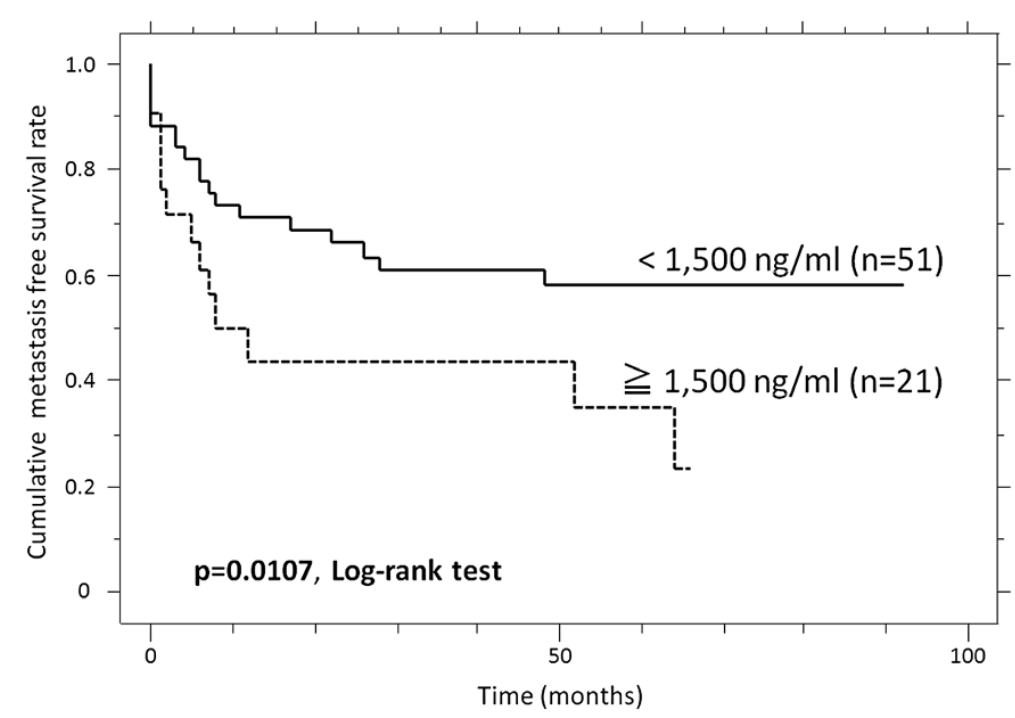

Figure 5 The cumulative metastasis-free survival (MFS) of patients with high SN-CAD levels, compared to patients with low $\mathrm{SN}$-CAD levels.

were associated with a decreased OS, DFS, MFS, and LRFS. The multivariate analyses showed an association of a high serum sN-CAD level with a decreased DFS. Therefore, our results suggest that a higher SN-CAD level is correlated with the local aggressiveness of the tumor.

In the present study, we confirmed that, poor overall survival was associated with high $\mathrm{SN}-\mathrm{CAD}$ and high histological grade in the univariate analysis. However, SN-CAD was failed to demonstrate any association with OS in multivariate analysis. The first possible reason is that $\mathrm{SN}-\mathrm{CAD}$ is not a strong predictor for OS compared with histological grading. The second possible reason is that multivariate analysis couldn't detect the sN-CAD as a strong predictor for OS, because this study consists of relatively small number of patients. Therefore, we think that the larger scale study is necessary.

Recent studies have demonstrated that $\mathrm{N}$-cadherin can be cleaved by ADAM10, which is one of the ADAM family members [8]. ADAM10 is a transmembrane protein involved in proteolysis and cell adhesion, and has been implicated in the pathogenesis or progression of several cancers, including uterine, ovarian, gastric and colorectal cancer [26]. There have so far been no reports

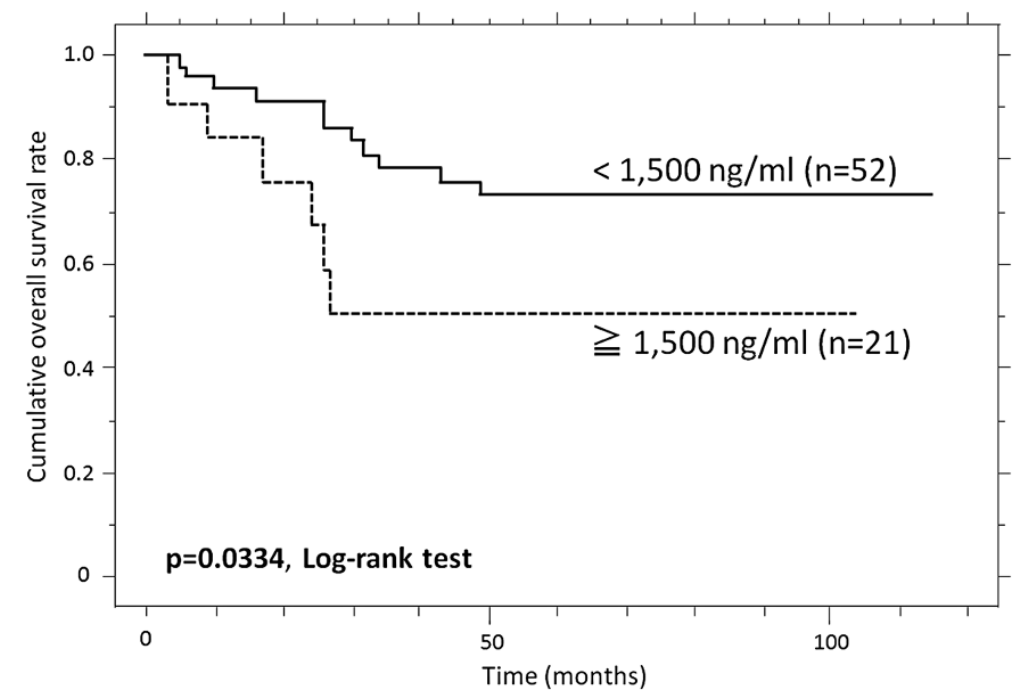

Figure 6 The cumulative overall survival (OS) of patients with high soluble N-cadherin (SN-CAD) levels, compared to patients with low sN-CAD levels. 


\begin{tabular}{|c|c|c|c|}
\hline $\begin{array}{l}\text { Clinicopathological } \\
\text { valiables }\end{array}$ & $\begin{array}{l}\text { Relative } \\
\text { risk }\end{array}$ & $\begin{array}{c}95 \% \text { confidence } \\
\text { interval }\end{array}$ & $p$ value \\
\hline Age (years) & 4.087 & $1.375-12.149$ & 0.0113 \\
\hline \multicolumn{4}{|l|}{$\leqq 49$} \\
\hline \multicolumn{4}{|l|}{$\geqq 50$} \\
\hline Size $(\mathrm{cm})$ & 2.816 & $0.624-12.706$ & 0.1779 \\
\hline \multicolumn{4}{|l|}{$<5$} \\
\hline \multicolumn{4}{|l|}{$\geqq 5$} \\
\hline Histological grading & 0.135 & $0.020-0.905$ & 0.0391 \\
\hline \multicolumn{4}{|l|}{ Low grade } \\
\hline \multicolumn{4}{|l|}{ High grade } \\
\hline Soluble Cadherin ${ }^{1}$ & 1.858 & $0.654-5.268$ & 0.2450 \\
\hline \multicolumn{4}{|l|}{ Low } \\
\hline High & & & \\
\hline
\end{tabular}

${ }^{1}$ Low means $<1,500 \mathrm{ng} / \mathrm{ml}$, and high means $\geqq 1,500 \mathrm{ng} / \mathrm{ml}$.

describing the ADAM10 expression in sarcoma tissue, but Matsumura et al. demonstrated that ADAM10 was expressed in a fibrosarcoma cell line [27]. The proteolytic activity of ADAM10 is inhibited by TIMP-1 and 3 $[6,8]$. Down-regulation of TIMP-1,-3 lead to deregulation of the TIMP-1, -3/ADAM10 pathway, with increased N-cadherin shedding. In fact, Benassi et al. [28] reported the TIMP-1 expression to be either weak or negative in the majority of 53 high grade soft tissue sarcoma samples, and concluded that low levels of negative regulators of proteolysis may be related to the biological aggressiveness of tumors. There was also a report demonstrating a lack of TIMPs expression in almost all high-grade osteosarcomas [29]. Other authors reported that no or minimal expression of TIMP-1 was detected in musculoskeletal sarcomas, and that there was a significant decrease of serum the TIMP-1 levels in sarcoma patients compared to healthy controls [30,31]. Therefore, we believe that the high sN-CAD expression level in high grade sarcoma patients might be the result of a disruption of the balance between the activation and suppression of N-cadherin shedding. Further investigations are therefore warranted.

The chief limitation of this study is the small number of samples examined. As is always the case in studies concerning bone and soft tissue sarcoma, a large number of samples could not be collected due to the rarity of the tumor. This makes it difficult to obtain blood samples from a large number of patients with each histopathology. In addition, bone and soft tissue sarcoma has a variety of pathological classifications, and we were only able to investigate a few samples from each pathological classification. As a result, a statistical analysis could not be performed for each pathological classification due to the small number of samples. The second limitation is that our samples were collected under various conditions, such as from the patients with primary sarcoma, sarcoma with multiple metastases, and so on. To improve the efficacy of using $\mathrm{sN}-\mathrm{CAD}$ as a biomarker, prospective longitudinal blood collection from numerous patients, for example, collection of blood preoperatively, ximmediately after surgery, and at the time when sarcoma recurs, is indispensible to improve the reliability of $\mathrm{sN}-\mathrm{CAD}$ as a biomarker. The third limitation is concerning the cut-off value. In this study, we determined the cut-off value in consideration of mean sN-CAD and clinical impact. As described above, a large number of samples could not be collected due to the rarity of the tumor and adequate cut-off value is not established. Further investigation is warrant.

Despite these limitations, we believe that this study is of great value for the diagnosis and treatment of these tumors. Clinically, tumor factors such as tumor-nodemetastasis staging, differentiation, histological classification, and the tumor size are known to have strong prognostic value. However, a prognostic indicator that could predict the operability, survival rate, and recurrence rate before the pathology of a resected specimen is available (and, hence, before surgery) would be particularly helpful. This would provide important guidance and clues for the selection of an optimal therapeutic approach. In this study, we identified that the pre-therapeutic level of sN-CAD could serve such a purpose, and could be determined by using a simple enzyme-linked immunosorbent assay.

\section{Conclusion}

In conclusion, our results indicate that $\mathrm{SN}-\mathrm{CAD}$ is present in significantly higher amounts in patients with malignant bone and soft tissue tumors than in healthy subjects. In addition, a high serum $\mathrm{sN}$-CAD level is associated with a poor outcome in musculoskeletal tumor patients. SN-CAD is therefore a potentially valuable pretherapeutic factor for predicting the long-term survival in patients. Further studies involving a larger sample and longer follow-up are necessary to verify these results.

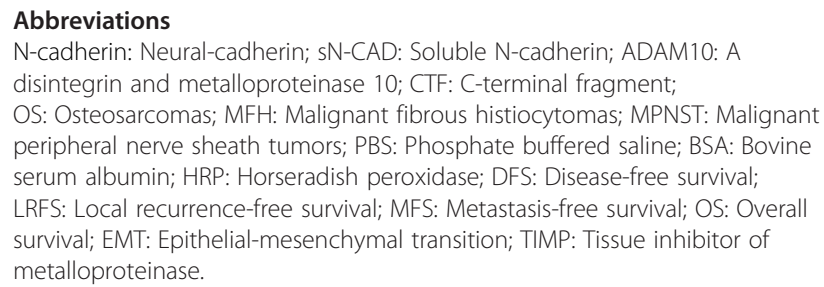

Competing interests

The authors declare that they have no competing interests. 


\section{Authors' contributions}

RN carried out plasma collection, statistical analysis, and drafted the manuscript. AM participated in study design, statistical analysis, and draft the manuscript. IT helped with the experiments. SN helped with the experiments. TN carried out analysis. AU directed the research project. AS drafted the manuscript and gave final approval of the manuscript. All authors read and approved the final manuscript.

\section{Acknowledgements}

The authors thank the staff members of Mie University Hospital, Shiokawa Hospital, and Toyama Hospital for their corporation with the blood sampling. We thank Mrs. Katsura Chiba and Miss Kayoko Oda for their diligence in preparing the clinical recordings. We gratefully acknowledge Marc Bracke for his technical advice.

\section{Author details}

'Department of Orthopaedic Surgery, Mie University Graduate School of Medicine, Tsu, Japan. ${ }^{2}$ Mie University, Tsu, Japan.

\section{Received: 29 August 2012 Accepted: 14 June 2013}

Published: 26 June 2013

\section{References}

1. Charalabopoulos K, Gogali A, Dalavaga Y, Daskalopoulos G, Vassiliou M, Bablekos G, Karakosta A, Constantopoulos S: The clinical significance of soluble E-cadherin in nonsmall cell lung cancer. Exp Oncol 2006, 28:83-85.

2. Cavallaro U, Schaffhauser B, Christofori G: Cadherins and the tumor progression: is it all in a switch? Cancer Lett 2002, 176:123-128.

3. Wheelock MJ, Johnson KR: Cadherins as modulators of cellular phenotype. Ann Rev Cell Dev Biol 2003, 19:207-235.

4. Baki L, Marambaud P, Efthimiopoulos S, Georgakopoulos A, Wen P, Cui W, Shioi J, Koo E, Ozawa M, Friedrich VL Jr, Robakis NK: Presenilin-1 binds cytoplasmic epithelial cadherin, inhibits cadherin/p120 association, and regulates stability and function of the cadherin/catenin adhesion complex. Proc Natl Acad Sci USA 2001, 98:2381-2386.

5. Jeanes A, Gottardi CJ, Yap AS: Cadherins and cancer: how does cadherin dysfunction promote tumor progression? Oncogene 2008, 27:6920-6929.

6. Maretzky T, Reiss K, Ludwig A, Buchholz J, Scholz F, Proksch E, De Strooper B, Hartmann D, Saftig P: ADAM10 mediates E-cadherin shedding and regulates epithelial cell-cell adhesion, migration, and beta-catenin translocation. Proc Natl Acad Sci USA 2005, 102:9182-9187.

7. Van Aken E, De Wever O, Da Rocha AS C, Mareel M: Defective E-cadherin /catenin complexes in human cancer. Virchows Arch 2001, 439:725-751.

8. Reiss K, Maretzky T, Ludwig A, Tousseyn T, De Strooper B, Hartmann D, Saftig P: ADAM10 cleavage of $\mathrm{N}$-cadherin and regulation of cell-cell adhesion and beta-catenin nuclear signalling. EMBO J 2005, 24:742-752.

9. Uemura K, Kuzuya A, Aoyagi N, Ando K, Shimozono Y, Ninomiya H, Shimohama S, Kinoshita A: Amyloid beta inhibits ectodomain shedding of $\mathrm{N}$-cadherin via down-regulation of cell-surface NMDA receptor. Neurosci 2007, 145:5-10

10. Chan AO, Lam SK, Chu KM, Lam CM, Kwok E, Leung SY, Yuen ST, Law SY, Hui WM, Lai KC, Wong CY, Hu HC, Lai CL, Wong J: Soluble E-cadherin is a valid prognostic marker in gastric carcinoma. Gut 2001, 48:808-811.

11. Jaggi M, Nazemi T, Abrahams NA, Baker JJ, Galich A, Smith LM, Balaji KC: $\mathrm{N}$-cadherin switching occurs in high Gleason grade prostate cancer. Prostate 2006, 66:193-199.

12. Nagi C, Guttman M, Jaffer S, Qiao R, Keren R, Triana A, Li M, Godbold J, Bleiweiss IJ, Hazan RB: N-cadherin expression in breast cancer: correlation with an aggressive histologic variant-invasive micropapillary carcinoma. Breast Cancer Res Treat 2005, 94:225-235.

13. Rieger-Christ KM, Cain JW, Braasch JW, Dugan JM, Silverman ML, Bouyounes B, Libertino JA, Summerhayes IC: Expression of classic cadherins type I in urothelial neoplastic progression. Hum Pathol 2001, 32:18-23.

14. Tomita K, Van Bokhoven A, Van Leenders GJLH, Ruijter ETG, Jansen CFJ, Bussemakers MJG, Schalken JA: Cadherin switching in human prostate cancer progression. Cancer Res 2000, 60:3650-3654.

15. Inwards $\mathrm{CY}$, Unni KK: Classification and grading of bone sarcomas. Hematol Oncol Clin North Am 1995, 9:545-569.

16. Guillou L, Coindre JM, Bonichon F, Nguyen BB, Terrier P, Collin F, Vilain MO, Mandard AM, Le Doussal V, Leroux A, Jacquemier J, Duplay H, Sastre-Garau
X, Costa J: Comparative study of the National Cancer Institute and French Federation of Cancer Centers Sarcoma Group grading systems in a population of 410 adult patients with soft tissue sarcoma. J Clin Oncol 1997, 15:350-362.

17. Derycke L, De Wever O, Stove V, Vanhoecke B, Delanghe J, Depypere H, Bracke M: Soluble N-cadherin in human biological fluids. Int I Cancer 2006, 119:2895-2900.

18. Voulgari A, Pintzas A: Epithelial-mesenchymal transition in cancer metastasis: mechanisms, markers and strategies to overcome drug resistance in the clinic. Biochim Biophys Acta 2009, 1796:75-90.

19. Foroni C, Broggini M, Generali D, Damia G: Epithelial-mesenchymal transition and breast cancer: Role, molecular mechanisms and clinical impact. Cancer Treat Rev 2012, 38:689-697.

20. Bailey T, Biddlestone L, Shepherd N, Barr H, Warner P, Jankowski J: Altered cadherin and catenin complexes in the Barrett's esophagus-dysplasiaadenocarcinoma sequence: Correlation with disease progression and dedifferentiation. Am J Pathol 1998, 152:135-144.

21. De Boer CJ, Van Dorst E, Van Krieken H, Jansen-van Rhijn CM, Warnaar SO, Fleuren GJ, Litvinov SV: Changing roles of cadherins and catenins during progression of squamous intraepithelial lesions in the uterine cervix. Am J Pathol 1999, 155:505-515.

22. Cho SB, Lee KH, Lee JH, Park SY, Lee WS, Park CH, Kim HS, Choi SK, Rew JS: Expression of $\mathrm{E}-$ and $\mathrm{N}$-cadherin and clinicopathology in hepatocellular carcinoma. Pathol Int 2008, 58:635-642.

23. Patel IS, Madan P, Getsios S, Bertrand MA, MacCalman CD: Cadherin switching in ovarian cancer progression. Int J Cancer 2003, 106:172-177.

24. Laskin WB, Miettinen M: Epithelial-type and neural-type cadherin expression in malignant noncarcinomatous neoplasms with epithelioid features that involve the soft tissues. Arch Pathol Lab Med 2002, 126:425-431.

25. Kashima T, Kawaguchi J, Takeshita S, Kuroda M, Takanashi M, Horiuchi H, Imamura T, Ishikawa Y, Ishida T, Mori S, Machinami R, Kudo A: Anomalous cadherin expression in osteosarcoma. Possible relationships to metastasis and morphogenesis. Am J Pathol 1999, 155:1549-1555.

26. Arribas J, Bech-Serra JJ, Santiago-Josefat B: ADAMs, cell migration and cancer. Cancer Metastasis Rev 2006, 25:57-68.

27. Matsumura S, Demaria S: Up-regulation of the Pro-inflammatory Chemokine CXCL16 is a Common Response of Tumor Cells to lonizing Radiation. Radiat Res 2010, 173:418-425.

28. Benassi MS, Magagnoli G, Ponticelli F, Pazzaglia L, Zanella L, Gamberi G, Ragazzini P, Ferrari C, Mercuri M, Picci P: Tissue and serum loss of metalloproteinase inhibitors in high grade soft tissue sarcomas. Histol Histopathol 2003, 18:1035-1040.

29. Ferrari C, Benassi S, Ponticelli F, Gamberi G, Ragazzini P, Pazzaglia L, Balladelli A, Bertoni F, Picci P: Role of MMP-9 and its tissue inhibitor TIMP-1 in human osteosarcoma: findings in 42 patients followed for 1-16 years. Acta Orthop Scand 2004, 75:487-491.

30. Berend KR, Toth AP, Harrelson JM, Layfield LI, Hey LA, Scully SP: Association between ratio of matrix metalloproteinase-1 to tissue inhibitor of metalloproteinase- 1 and local recurrence, metastasis, and survival in human chondrosarcoma. J Bone Joint Surg Am 1998, 80:11-17.

31. Roebuck MM, Helliwell TR, Chaudhry IH, Kalogrianitis S, Carter S, Kemp GJ, Ritchie DA, Jane MJ, Frostick SP: Matrix metalloproteinase expression is related to angiogenesis and histologic grade in spindle cell soft tissue neoplasms of the extremities. Am J Clin Pathol 2005, 123:405-414.

doi:10.1186/1471-2407-13-309

Cite this article as: Niimi et al: Soluble Neural-cadherin as a novel biomarker for malignant bone and soft tissue tumors. BMC Cancer 2013 13:309. 